\title{
Correction to: Modeling of Superelastic-plastic Behavior of Porous Shape Memory Alloys Incorporating Void Shape Effects $^{\star \star}$
}

\author{
Xiang Zhu ${ }^{1} \quad$ Guansuo Dui ${ }^{1 \star(1)}$ \\ ( ${ }^{1}$ Institute of Mechanics, Beijing Jiaotong University, Beijing 100044, China) \\ published online 10 March 2021 \\ (C) The Chinese Society of Theoretical and Applied Mechanics 2021
}

\section{Correction to: Acta Mechanica Solida Sinica https://doi.org/10.1007/s10338-021-00214-2}

During production of the article unfortunately a typesetting mistake has been introduced in Eq. (3). The correct equation is:

$$
\Phi(\Sigma, \xi, f)=Q \frac{\left(\Sigma_{e q}+\omega \Sigma_{m}\right)^{2}}{\sigma_{0}^{2}}+2 f \cosh \left(\frac{\kappa \Sigma_{m}}{\sigma_{0}}\right)-1-f^{2}=0
$$

The original article has been corrected.

\footnotetext{
* Corresponding author. E-mail: gsdui@bjtu.edu.cn

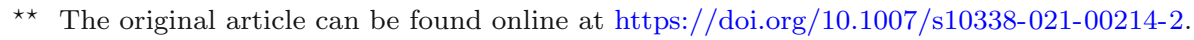

